\title{
Sorafenib for the treatment of hepatocellular carcinoma: a single-centre real-world study
}

\author{
Jurij Hanzel ${ }^{1}$, Tajda Kosir Bozic ${ }^{1}$, Borut Stabuc ${ }^{1,2}$, Rado Jansa ${ }^{1,2}$ \\ 1 Department of Gastroenterology, University Medical Centre Ljubljana, Ljubljana, Slovenia \\ 2 Faculty of Medicine, University of Ljubljana, Ljubljana, Slovenia
}

Radiol Oncol 2020; 54(2): 233-236.

Received 18 November 2019

Accepted 1 December 2019

Correspondence to: Rado Janša, Ph.D., M.D., Department of Gastroenterology, University Medical Centre Ljubljana, Japljeva ulica 2, SI-1000 Ljubljana, Slovenia. E-mail: rado.jansa@kclj.si

Disclosure: No potential conflicts of interest were disclosed.

Background. Sorafenib is an oral multi-kinase inhibitor used for the treatment of hepatocellular carcinoma. Its efficacy in randomised controlled trials was demonstrated in patients with well-preserved liver function and good functional status. In the real-world setting, treatment is often offered to patients outside these criteria. We therefore performed a single-centre real-world cohort study on the efficacy of sorafenib in patients with hepatocellular carcinoma.

Patients and methods. We identified all patients with hepatocellular carcinoma initiating treatment with sorafenib between January 2015 and January 2018. The primary endpoint was overall survival (OS) since starting sorafenib. Clinical and demographic variables associated with survival were studied.

Results. The median OS was 13.4 months (95\% Cl 8.2-18.6). Multivariable Cox's regression identified worse ECOG performance status (HR 2.21; 95\% Cl 1.56-3.16; $P<0.0001$ ), Child-Pugh class $C$ (HR 52.4; 95\% Cl 3.20-859; $P=0.005$ ) and absence of prior locoregional treatment (HR 2.30; $95 \% \mathrm{Cl} 1.37-3.86 ; P=0.002$ ) to be associated with increased mortality. Conclusions. Careful selection of patients for treatment with sorafenib is of paramount importance to optimize outcomes.

Key words: survival; multivariable analysis; real-world cohort study

\section{Introduction}

Sorafenib is an oral multi-kinase inhibitor, which inhibits tumours angiogenesis through inhibition of vascular endothelial growth factor (VEGF) and platelet-derived growth factor (PDGF) signalling pathways. It has demonstrated a significant prolongation in overall survival of patients with advanced-stage hepatocellular carcinoma (HCC) up to 2.8 months. ${ }^{1,2}$ The two landmark trials included mainly patients with compensated liver cirrhosis of viral aetiology and an excellent baseline functional status. Consequently, sorafenib is formally indicated only in patients with well-preserved liver function (Child-Pugh A) and advanced tumours (Barcelona Clinic Liver Cancer [BCLC] C) or intermediate stage tumours (BCLC B) progressing after locoregional therapy. ${ }^{3}$
Nevertheless, sorafenib is often used outside these criteria in the real-world setting, mainly due to the absence of alternative treatment options. As these patient subgroups were not studied in registrational trials, only large observational non-randomized cohort studies can help inform practice. ${ }^{4-6}$

We therefore a retrospective real-world cohort study of patients treated with sorafenib for advanced HCC, investigating its efficacy and variables associated with OS.

\section{Patients and methods}

\section{Patients and study design}

We performed a retrospective cohort study of all patients with HCC initiating treatment with sorafenib between January 2015 and January 2018, 
who were followed until October 2018 at a single tertiary centre. Data collection was approved by the institutional ethics committee, while treatment did not differ from the standard of care and thus did not require additional approval.

We included all consecutive patients aged at least 18 years with a histologically or radiologically confirmed diagnosis of HCC, who were treated with sorafenib. The decision for initiation of the drug was made based on the consensus of the Liver Multidisciplinary Team. Patient records were retrospectively reviewed for demographic and clinical information. The date of death was extracted from the national health insurance database.

The primary outcome was OS from initiation of sorafenib. We explored the relationship of clinical characteristics with OS.

\section{Statistical analysis}

Continuous variables are given as medians with interquartile ranges (IQR). Univariable association analyses with survival were performed using the Kaplan-Meier method with log-rank testing. Multivariable analysis was performed using a Cox-proportional hazards model with stepwise backward selection where variables were removed if they did not achieve statistical significance at $P$ $<0.05$. All analyses were performed on an intention-to-treat basis. Analyses were performed using SPSS, Version 25 (IBM, Chicago, USA).

\section{Results}

\section{Patient characteristics}

We included 115 patients, who were predominantly male with Child-Pugh class A alcoholic cirrhosis with good performance status (Table 1).

\section{Survival outcomes}

A total of 83 patients $(72 \%)$ died during the study period. The median OS since initiation of sorafenib was 13.4 months (95\% CI 8.2-18.6).

In univariable analysis, reduced OS was associated with worse ECOG performance status $(P<$ $0.0001)$, higher Child-Pugh class $(P<0.0001)$, higher baseline AFP $(P=0.003)$ and absence of prior locoregional treatment $(P<0.0001)$ (Table 2$)$. The associations of liver disease aetiology $(P=0.192)$, BCLC stage $(P=0.539)$, gender $(P=0.944)$ and age at treatment initiation $(P=0.201)$ with OS were not statistically significant.
TABLE 1. Patient characteristics at initiation of sorafenib $(\mathrm{n}=$ 115)

\begin{tabular}{|c|c|}
\hline \multicolumn{2}{|l|}{ Variable } \\
\hline Male gender, n (\%) & $96(84)$ \\
\hline Age, years, median (IQR) & $67(60-72)$ \\
\hline $\begin{array}{l}\text { ECOG performance status } \\
0 \\
1 \\
2 \\
3\end{array}$ & $\begin{aligned} 31 & (27) \\
47 & (40.9) \\
36 & (31.3) \\
1 & (0.9)\end{aligned}$ \\
\hline $\begin{array}{l}\text { Aetiology of underlying liver disea } \\
\text { Alcoholic liver disease } \\
\text { Hepatitis B } \\
\text { Hepatitis C } \\
\text { Non-alcoholic steatohepatitis } \\
\text { Cryptogenic } \\
\text { Wilson's disease } \\
\text { Primary biliary cholangitis } \\
\text { HCC in non-cirrhotic liver }\end{array}$ & $\begin{array}{c}56(49) \\
11(9.6) \\
7(6.1) \\
18(15.7) \\
10(8.7) \\
1(0.9) \\
1(0.9) \\
11(9.6)\end{array}$ \\
\hline $\begin{array}{l}\text { Child-Pugh class, n (\%) } \\
\text { A } \\
\text { B } \\
\text { C }\end{array}$ & $\begin{array}{c}77(66.9) \\
37(32.2) \\
1(0.9)\end{array}$ \\
\hline \multicolumn{2}{|l|}{ BCLC stage, n (\%) } \\
\hline $\begin{array}{l}A \\
B \\
C\end{array}$ & $\begin{array}{c}3(2.6) \\
42(36.5) \\
70(60.9)\end{array}$ \\
\hline Prior treatment, n (\%) & $45(39.1)$ \\
\hline $\begin{array}{l}\text { Resection } \\
\text { RFA } \\
\text { Transplant } \\
\text { TACE } \\
\text { Radioembolization }\end{array}$ & $\begin{aligned} 10 & (8.7) \\
2 & (1.8) \\
3 & (2.6) \\
29 & (25.2) \\
5 & (4.3)\end{aligned}$ \\
\hline AFP, kU/L, median (IQR) & $6-1518)$ \\
\hline
\end{tabular}

AFP = alpha-fetoprotein; $B C L C=$ Barcelona Clinic Liver Cancer; $E C O G=$ Eastern Cooperative Oncology Group; $\mathrm{HCC}=$ hepatocellular carcinoma; $I Q R=$ interquartile range; $R F A=$ radiofrequency ablation; $T A C E=$ transarterial chemoembolization

Multivariable analysis demonstrated significant associations between mortality and ECOG performance status (HR 2.21; 95\% CI 1.56-3.16; $P<$ 0.0001), Child-Pugh class C (HR 52.4; 95\% CI 3.20859; $P=0.005)$ and absence of prior locoregional treatment (HR 2.30; 95\% CI 1.37-3.86; $P=0.002$ ), but not baseline AFP (HR 1.00; 95\% CI 0.8-1.2; $P=$ 0.278) (Table 2, Figure 1).

\section{Discussion}

HCC is among the leading causes of cancer-related deaths. It primarily develops from cirrhosis, and many patients are infected with hepatitis $C$ virus (HCV) or hepatitis B virus (HBV). Treatment with the multikinase inhibitor sorafenib is a systemic therapy option for patients with advanced HCC since 2008. 

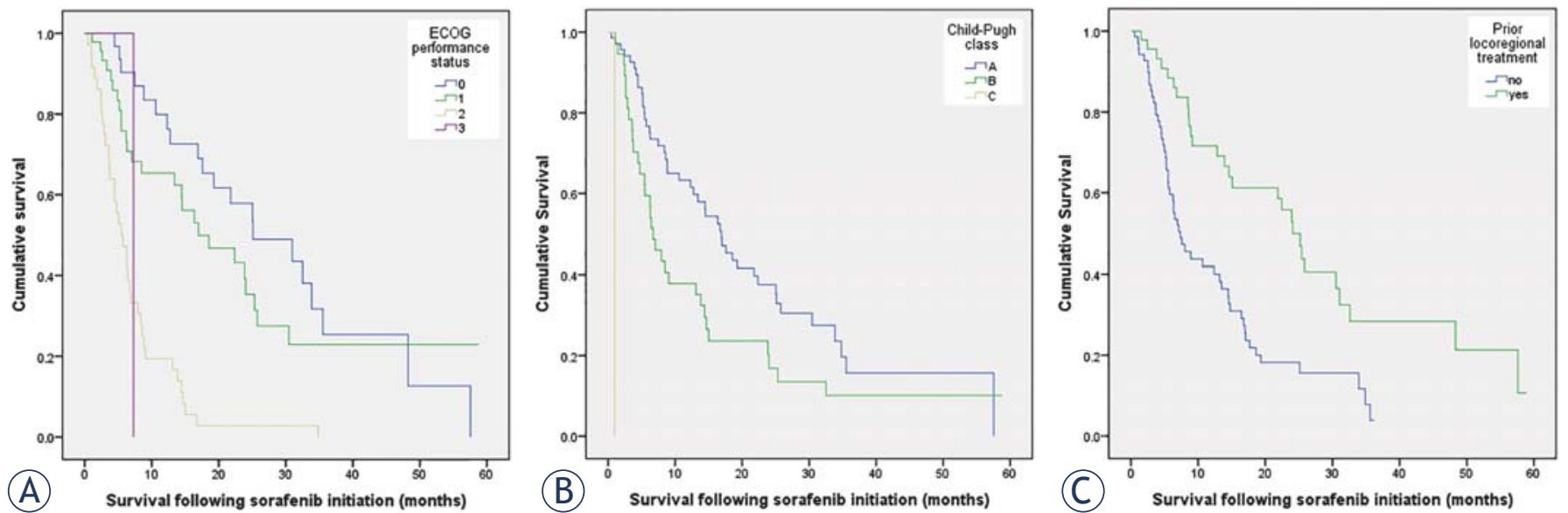

FIGURE 1. Kaplan-Meier plots of overall survival (OS) after initiating sorafenib stratified by (A) ECOG performance status, (B) Child-Pugh class, and (C) prior locoregional treatment.

Systemic therapy has helped prolong survival after disease progression. Clinical management of patients should target improvement of patient OS. Sorafenib therapy is recommended in guidelines as the first-line option in patients who cannot benefit from resection, transplantation, ablation or TACE, and still have preserved liver function and significantly prolonged OS and TTP.

Sorafenib monotherapy remains the standard of care in unresectable HCC. Sorafenib has demonstrated survival benefit in patients with unresectable HCC in two (2) randomized, placebo-con-

TABLE 2. Factors associated with overall survival (OS) after initiation of sorafenib

\begin{tabular}{|c|c|c|c|c|}
\hline & \multicolumn{2}{|c|}{ Univariable analysis } & \multicolumn{2}{|c|}{ Multivariable analysis } \\
\hline & $\begin{array}{l}\text { Median survival in } \\
\text { months }(95 \% \mathrm{Cl})\end{array}$ & Log rank $P$ value & $\begin{array}{l}\text { Hazard ratio }(95 \% \\
\mathrm{Cl})\end{array}$ & $\begin{array}{c}\text { Cox's regression } P \\
\text { value }\end{array}$ \\
\hline $\begin{array}{l}\text { ECOG performance status } \\
0 \\
1 \\
2 \\
3\end{array}$ & $\begin{array}{c}25.1(12.8-37.4) \\
17.0(7.0-26.9) \\
5.5(3.7-7.3) \\
7.3(/)\end{array}$ & $<0.0001$ & $2.21(1.56-3.16)$ & $<0.0001$ \\
\hline $\begin{array}{l}\text { Child-Pugh class } \\
\text { A } \\
\text { B } \\
\text { C }\end{array}$ & $\begin{array}{c}16.9(12.8-21.0) \\
6.7(4.7-8.7) \\
1.0(/)\end{array}$ & $<0.0001$ & $\begin{array}{c}1.00 \\
1.34(0.80-2.26) \\
52.4(3.20-859)\end{array}$ & $\begin{array}{l}0.271 \\
0.005\end{array}$ \\
\hline $\begin{array}{l}\text { Baseline AFP } \\
\quad<200 \\
\quad \geq 200\end{array}$ & $\begin{array}{r}17.0(9.3-24.6) \\
6.7(5.6-7.8)\end{array}$ & 0.003 & $1.00(0.8-1.2)$ & 0.278 \\
\hline $\begin{array}{l}\text { Prior locoregional treatment } \\
\text { Yes } \\
\text { No }\end{array}$ & $\begin{array}{c}24.0(20.1-27.9) \\
7.3(5.0-9.5)\end{array}$ & $<0.0001$ & $\begin{array}{c}1.00 \\
2.30(1.37-3.86)\end{array}$ & 0.002 \\
\hline $\begin{array}{l}\text { Liver disease aetiology } \\
\text { Alcoholic } \\
\text { Other }\end{array}$ & $\begin{array}{c}8.6(3.80-13.3) \\
16.7(13.5-19.9)\end{array}$ & 0.192 & & \\
\hline $\begin{array}{l}\text { BCLC stage } \\
\text { A } \\
\text { B } \\
\text { C }\end{array}$ & $\begin{array}{l}22.4(7.0-37.7) \\
14.5(5.1-23.9) \\
13.4(7.1-19.7)\end{array}$ & 0.539 & & \\
\hline $\begin{array}{l}\text { Gender } \\
\text { Female } \\
\text { Male }\end{array}$ & $\begin{array}{c}8.8(7.0-10.7) \\
13.8(10.1-17.6)\end{array}$ & 0.944 & & \\
\hline $\begin{array}{l}\text { Age } \\
<70 \text { years } \\
\geq 70 \text { years }\end{array}$ & $\begin{array}{r}15.0(11.2-18.8) \\
8.4(6.0-10.8)\end{array}$ & 0.201 & & \\
\hline
\end{tabular}

AFP = alpha-fetoprotein; BCLC = Barcelona Clinic Liver Cancer; ECOG = Eastern Cooperative Oncology Group; IQR = interquartile range 
trolled, double-blind, phase III trials: SHARP and AP. The use of sorafenib significantly increased OS: 10.7 months vs. 7.9 months (SHARP study) and radiologic progression was significantly lower in the sorafenib group of patients. ${ }^{8}$

The use of Sorafenib also significantly increased OS in Asian-Pacific study. However, the results compared with SHARP study were worst especially because of different demographic characteristics of patients, more extrahepatic spread, greater number of hepatic tumor lesions and poorer ECOG performance status.

In GIDEON, real life analysis of the sorafenib group of patients median OS was 8.6 month vs. 10.4 in SHARP study. Clinical outcomes of advanced HCC patients treated with sorafenib in real-life practice are better compared to the other studies conducted in the Asia-Pacific region in terms of survival and tolerability. Extrahepatic spread and combination with other therapies are of predictive value for OS of advanced HCC. Further studies are required to maximize the effect of sorafenib in combination with other modalities. ${ }^{7,8}$

In our retrospective study, we collected and analyzed the clinical outcomes of advanced HCC patients who underwent treatment with sorafenib in real-life clinical setting. We found that HCC patients with Child-Pugh A exhibited a significantly higher median survival. In the present study, factors that are predictive of OS in HCC patient treated with sorafenib include gender, extrahepatic spread, and combined other therapies. ${ }^{7,8}$

In the Slovenian study, HCC patients treated with sorafenib had median OS of 13.4 months, which is longer than that reported in SHARP (10.5 months) and GIDEON (Global Investigation of Therapeutic Decisions in HCC and of its treatment with sorafenib) (10.8 months).

Multivariable analysis of the Slovenian group of patients demonstrated significant associations between mortality and ECOG performance status, Child-Pugh class $\mathrm{C}$ and absence of prior locoregional treatment, but not baseline AFP.

There are several limitations in this retrospective designed analysis. Being a retrospective study, it is difficult to ascertain the actual cause of death in our cohort. The population size examined in our study is relatively small, which may limit the statistical power. Small population size may have influences on subgroup analysis. Other limitations include the reduced initial dose of sorafenib based on clinical decision made by individual physicians and adjustment of dosages during treatment due to intolerance.
However, our results are comparable with results of other worldwide studies.

In conclusions, careful selection of patients for sorafenib treatment is important. Treatment of HCC patients should be performed in experienced centers, where the decision of treatment of each patients should be made after previous presentation of patients at multidisciplinary board of experts.

\section{References}

1 Llovet JM, Hilgard P, de Oliveira AC, Hilgard P, Gane E, Blanc JF, et al. Sorafenib in Advanced Hepatocellular Carcinoma. N Engl J Med 2008; 13: 378-90. doi: 10.1056/NEJMoa0708857

2 Cheng AL, Kang YK, Chen Z, Tsao CJ, Qin S, Kim JS, et al. Efficacy and safety of sorafenib in patients in the Asia-Pacific region with advanced hepatocellular carcinoma: a phase III randomised, double-blind, placebo-controlled trial. Lancet Oncol 2009; 10: 25-34. doi: 10.1016/S1470-2045(08)70285-7

3 Vogel A, Cervantes A, Chau I, Daniele B, Llovet JM, Meyer T, et al. Hepatocellular carcinoma: ESMO Clinical Practice Guidelines for diagnosis, treatment and follow-up. Ann Oncol 2018; 29(Suppl 4): iv238-55. doi: 10.1093/annonc/mdy308

4 Marrero JA, Kudo $\mathrm{M}$, Venook AP, Ye SL, Bronowicki JP, Chen XP, et al. Observational registry of sorafenib use in clinical practice across Child-Pugh subgroups: The GIDEON study. J Hepatol 2016; 65: 1140-7. doi: 10.1016/j. jhep.2016.07.020

5 Lee S, Kim BK, Kim SU, Park SY, Kim JK, Lee HW, et al. Clinical outcomes and prognostic factors of patients with advanced hepatocellular carcinoma treated with sorafenib as first-line therapy: a Korean multicenter study: Sorafenib as a first-line therapy. J Gastroenterol Hepatol 2014; 29: 1463-9. doi: $10.1111 /$ jgh.12542

6 Doyle A, Marsh P, Gill R, Rodov M, Mohsen W, Varma P, et al. Sorafenib in the treatment of hepatocellular carcinoma: a multicentre real-world study. Scand J Gastroenterol 2016; 51: 979-85. doi: 10.3109/00365521.2016.1166518

7 Llovet LM, Bruix J. Management of HCC. Hepathology 2008; 48: 1312-27. doi: 10.1002/hep.22506.

8 Forner A, Llovet LM, Bruix J. Hepatocellular carcinoma. Lancet 2012; 379: 1245-55. doi: 10.1016/S0140-6736(11)61347-0 